\title{
VIRTUAL REPATRIATION: THE PITTSBURGH-KONSTANZ ARCHIVAL PARTNERSHIP
}

DURING THE 1920s AND 1930s, a group of German and Austrian thinkers pioneered an approach to philosophy that shaped much of the discipline's subsequent development. These thinkers were "inspired by late nineteenth- and early twentieth-century revolutions in logic, mathematics and mathematical physics" and "aimed to create a similarly revolutionary scientific philosophy purged of the endless controversies" 1 that had traditionally occupied philosophers. The result was a style of doing philosophy known as logical positivism. Berlin and Vienna were its main centers. The proponents of logical positivism included, among others, Rudolf Carnap, Herbert Feigl, Carl Hempel, and Hans Reichenbach. The logical positivists met regularly for lectures and discussions, organized international conferences, and published the journal Erkenntnis ("Knowledge") to promote their ideas. The movement was at its peak from 1928 to 1934, but the rise of National Socialism eventually forced most of its leading representatives to emigrate. Many settled permanently in the United States, holding appointments at institutions such as Chicago, Princeton, and UCLA. They were well received by most American philosophers, whose pragmatic, empirical approach dovetailed with logical positivism's scientific character. In their new homeland, the logical positivists "exerted a tremendous influence-particularly in philosophy of science and the application of logical and mathematical techniques to philosophical problems more generally." 2

These émigrés trained some of the most prominent American philosophers of the next generation, several of whom became faculty members at the University of Pittsburgh. By the 1970s, Pittsburgh's

1. Michael Friedman, "Logical Positivism," in Routledge Encyclopedia of Philosophy, ed. E. Craig (London: Routledge, 1998), v. 5, 789.

2. Ibid., 790 . 
philosophy department ranked among the best in the nation and was the leader in the scientific approach to philosophy that evolved from logical positivism. By the same time, key members of the immigrant generation had died. They had brought from Europe sizeable collections of personal and professional papers which they augmented in the U.S. As these collections became available, the University of Pittsburgh acquired several, believing itself to be the natural repository for logical positivism's documentary legacy. In 1979, Pittsburgh established the Archives of Scientific Philosophy (ASP), housed in the Special Collections Department of its central library. In its early days, the ASP consisted of the papers of Rudolf Carnap and Hans Reichenbach, two of logical positivism's best-known proponents. These highprofile collections soon attracted several others, including the papers of Herbert Feigl and Carl Hempel. ${ }^{3}$ Moreover, philosophers working in the logical positivist tradition were becoming increasingly interested in its history, which guaranteed the ASP a steady and even growing usership. Less than a decade after the ASP had opened, a position was created for a full-time, professional curator to assist the increasing number of researchers, process newly acquired collections, and work on obtaining others. The scholarly significance of the ASP is clear from both the variety and the quantity of its users. They come from six continents and many disciplines, including philosophy, history of science, German literature, sociology, political science, economics, and education. The majority of researchers are faculty members, although graduate students have always numbered among the collections' users. To date, 57 books, 156 articles, and 10 dissertations that draw on the ASP have been published. ${ }^{4}$

During the 1970s and 1980s, the University of Konstanz, in Germany, also was assembling an archive documenting the rise of scientific philosophy. Known as the Philosophisches Archiv, this material was both physically and administratively part of the university's Center for Philosophy of Science. The scope of Konstanz's archive was modest, however, in comparison to Pittsburgh's, and management of the collections was left to a philosophy professor who had many other duties. Konstanz was eager to increase its holdings and to establish a profes-

3. For detailed description of the ASP's collections, visit http://www.library.pitt.edu/libraries/special/asp/archive.html.

4. For a complete bibliography, visit http://www.library.pitt.edu/libraries/special/asp/user. html. 
sionally run archive that would attract more users. At the same time, Pittsburgh was looking for ways to better serve its growing and seemingly permanent European usership. By the late 1980s, nearly half of all ASP users were European, mostly from German-speaking countries. These individuals had to spend considerable time and money visiting Pittsburgh in order to pursue their research. For those unable to travel, the staff of the ASP would perform limited research and provide photocopies of relevant documents at cost. Demand for this service became so great, however, that a ceiling of two hundred copies per patron soon had to be imposed. The large volume of European users was clearly putting a strain on the ASP's staff, preventing it from processing new acquisitions and performing other important responsibilities. A way was needed to serve Europeans more efficiently and at less cost to themselves. In short, the ASP and the Philosophisches Archiv had needs that could be met by working together. They therefore entered into a unique partnership.

The broad provisions of this partnership were formulated in an "Agreement of Archival Collaboration" dated January 16, 1990, and signed by the chief administrative officer of each university. According to the agreement, Pittsburgh would deposit complete copies of its collections at Konstanz. The copies would become part of the Philosophisches Archiv and would be available under the same user-friendly conditions as they were in Pittsburgh. In addition, Pittsburgh would provide training for Konstanz's first full-time curator and professional support as that repository assumed its new role. Using money obtained from public funding agencies in Germany, for its part Konstanz would cover the costs of duplication, training, and related activities. The bill for all this would run to six figures. Nevertheless, both sides knew that housing copies of the ASP's collections in Konstanz would greatly improve access to them for European researchers, especially for Germans and Austrians.

Implementation of the partnership stretched over several years. Preservation microfilming according to RLG and ANSI standards was consciously chosen over other means of duplicating the ASP's collections. Photocopying, for example, was rejected because the long-term effects of toner on paper were unknown. Digitizing was too new and untried at the time to be seriously considered. Because Pittsburgh had neither the equipment nor the staff to microfilm its collections, a suitable vendor had to be found. UMI, which was still filming archival material in the early 1990s, was highly regarded by preservation librarians and thus was 
the vendor selected. Student workers were hired and trained to prepare the ASP's three open collections for filming. They produced and placed standard microfilming targets throughout the collections, programmed all the reels, and packed material for shipping. At times, two students were each working nearly forty hours per week on preparation. When all was said and done, UPS transported fifty-two linear feet of material to and from UMI. As a precaution, material was sent both directions in several small shipments, although nothing was ever lost or damaged. Student workers also checked each reel of microfilm produced against the paper originals, frame by frame. Only occasional retakes were necessary. Approved reels were sent to Konstanz in small shipments by U.S. Mail and accompanied by a special customs declaration in German. Thus, the services of a customs broker were unnecessary. The first reels arrived in Konstanz in the fall of 1992. By 1994, a total of seventy-one reels had been sent, none of which was lost or damaged en route. Konstanz now possessed the entire Carnap (forty-one reels), Ramsey (two reels), and Reichenbach (twenty-eight reels) collections on microfilm. ${ }^{5}$ Availability of the material was publicized by an announcement in the journal Information Philosophie, which German-speaking philosophers read for news about the discipline. A similar announcement was posted to HOPOS-L, the premier listserv for the history of the philosophy of science.

Training also was an important component of the partnership. Because subject expertise was critical, Konstanz hired one of its recent Ph.D.'s to be the first professional curator of its archive. Her knowledge of twentieth-century philosophy was impeccable, but she had no education in librarianship or archival science. Remedying this deficit through formal study was not feasible. Library and archival training programs in Germany require several years of full-time study to complete, and none were located within commuting distance of Konstanz. At the time, Konstanz's curator was an employee of the university's Center for Philosophy of Science and thus could expect only minimal support from her institution's library. Consequently, the ASP's curator was enlisted to train his counterpart. In the spring of 1992, he spent a month in Konstanz educating her in the basics of cataloging, preservation, access policies, and general archival management. Pederson

5. In a subsequent microfilming project funded by Konstanz, Pittsburgh duplicated the papers of Herbert Feigl for both institutions. Owned by the University of Minnesota, the Feigl collection was loaned to the ASP to be organized, inventoried, and filmed.The twenty-five reels of this collection became available in Konstanz during the academic year 1995-1996. 
and McCausland's Keeping Archives ${ }^{6}$ proved a useful textbook, supplemented by selections from SAA's Basic Manual Series and articles from professional journals. Pittsburgh's curator made follow-up visits for training in the summers of 1994 and 1995, staying about a month each time. Between visits, questions and professional issues were addressed by e-mail, fax, or the telephone. Such communication occurred at least once a week and sometimes even daily. Over the years, the ASP's curator probably spent as much time training or supporting his counterpart from a distance as he did in Konstanz.

In 1999, the ASP was twenty years old, and Konstanz had a fully functioning, professionally managed archive. ${ }^{7}$ The microfilms of Pittsburgh's collections were, as expected, receiving steady, substantial use. But the partnership was not over. As originally envisioned, the two institutions plan to collaborate indefinitely. ${ }^{8}$ As each acquires collections of interest to the other, they will swap microfilm copies or underwrite the costs of obtaining such copies. Konstanz, for example, will certainly want to acquire a copy of the Carl Hempel collection after Pittsburgh has finished processing it.

Those are the historical high points of the Pittsburgh-Konstanz archival partnership. Three motives lay behind this collaboration. One was the belief that "repatriating" the content of logical positivism's documentary legacy was inherently worth doing. Germany and Austria certainly had no legal or moral claim to the ASP's collections because they had forced their creators to emigrate. Yet nobody could deny that the collections were largely the cultural product of German-speaking countries and had in this sense suffered displacement. Moreover, Pittsburgh stood to lose nothing by depositing copies of the material in Konstanz. Therefore, returning this important piece of cultural patrimony, albeit reformatted, seemed the honorable thing to do. In grant applications, Konstanz reminded German funding agencies that past wrongs could be partially righted by supporting virtual repatriation of the émigré collections. The other reasons for collaborating were purely practical. Consisting of highly acidic paper, many documents in the ASP had become so brittle that they could no longer sustain even careful handling.

6. Ann E. Pederson and Sigrid McCausland, Keeping Archives (Sydney:Australian Society of Archivists, 1987).

7. For further information about the collections and services of the Philosophisches Archiv, visit http://www.uni-konstanz.de/FuF/Philo/philarchiv/index2.htm.

8. In their "Agreement of Archival Collaboration," mentioned above, the two universities "declare their intention that the duration of this Agreement be perpetual." 
Pittsburgh's desire to preserve these important materials made the prospect of microfilming them for Konstanz very attractive. Negatives of the filmed collections would serve as a safeguard against deteriorating paper. The ASP's large European usership also motivated Pittsburgh to collaborate. As mentioned above, before the partnership nearly half of all ASP users were European, mostly from German-speaking countries. Their heavy use of the collections put a strain on Pittsburgh's staff. In the academic year 1990-1991, for instance, almost 3,700 pages of photocopies were made for users of the Carnap, Ramsey, and Reichenbach collections, the first that would be duplicated for Konstanz. A substantial number of these copies was for Europeans. Producing such a quantity of photocopies meant diverting resources from other key activities such as processing newly acquired collections. Attending to European visitors, who sometimes worked on-site for weeks or even months, also consumed many valuable staff hours. Because Pittsburgh's library system was experiencing fiscal constraints, hiring more staff was not an option. The only way to deal with the tide of European researchers was to send them elsewhere.

That solution has indeed worked. In the academic year 2002-2003, the latest for which statistics have been compiled, the ASP produced 1,150 pages of photocopies for users of the first three collections it microfilmed. This is roughly a third of the number of copies it made in 19901991, the year before the collections began to be available in Konstanz. The number of ASP users also markedly declined. In 1990-1991, a total of 154 researchers consulted the three collections. In 2002-2003, the same statistic was 101, a decrease of 34 percent. These days, Europeans use material in Pittsburgh infrequently. The few who do are generally in the U.S. for a sabbatical or a conference and thus find it convenient to make a side trip there. In short, for several years now the ASP's staff has had more time for acquiring and processing collections than it ever had before the partnership. As a collateral benefit, Pittsburgh has obtained high-quality microfilm negatives of its collections. Given the stiff competition for preservation funds in the U.S., microfilming the ASP's holdings may well not have occurred if Pittsburgh had been limited to American agencies for financial support.

Konstanz has benefited from the partnership in ways besides those already mentioned. After the ASP curator's first training visit, Konstanz began using MicroMARC, a microcomputer collections management system, to catalog its collections at the file folder level. This move 
entailed wholesale adoption of American cataloging standards and has distinguished the Philosophisches Archiv among German repositories. Germany still does not have a nationally accepted body of cataloging rules for libraries. Instead "numerous cataloging and classification systems are used ... including a multitude of homegrown ones." The situation in archives, especially in those collecting personal papers, is even less standardized. By deciding to use USMARC and AACR2, Konstanz transcended the cataloging idiosyncrasies perpetuated by other German institutions. This certainly has helped it in the funding arena. For years, the Deutsche Forschungsgemeinschaft (DFG), the largest German funding agency for research, has attempted to introduce uniformity into archival cataloging practice. Konstanz's applications for DFG support have received favorable consideration, in part because Konstanz adheres to a cataloging standard that is becoming more international by the year. Collaboration with Pittsburgh also facilitated administrative transfer of the Philosophisches Archiv and its curator to the university library. As a rule, German libraries and archives are strictly separate operations. The Philosophisches Archiv, for example, was originally a charge of the university's Center for Philosophy of Science. During the course of many discussions, Konstanz's curator learned from her Pittsburgh counterpart about the advantages of working in a university library. She found the possibility of ready practical support, a shared professional ethos, and collegiality appealing. Therefore, when she had an opportunity to join the staff of her institution's library, she gladly accepted it. Eight years later, she reports that she has no regrets and believes that she has become a more effective professional as a result of this arrangement. The Pittsburgh-Konstanz partnership has, then, resulted in the benefits that were hoped for as well as in ones that could scarcely have been anticipated.

The partnership's impressive results did not come easily at first. Difficulties posed by both intellectual property rights and Pittsburgh's outsourcing regulations delayed implementation by two years. Two of the three ASP collections to be filmed initially were acquired by contracts of sale that reserved intellectual property rights to the respective seller. These contracts had been executed in the U.S. and specified an American venue of jurisdiction in case of disputes. Thus, U.S. copyright law was invoked to justify filming both collections for Konstanz. According to the law, Pittsburgh could deposit a copy of unpublished material it owned in another library 
or archives for research use. ${ }^{10}$ However, the University Counsel's office objected, stating that the many journal articles and published manuscripts in the ASP's collections should not be treated this way. Publications, it maintained, could not be systematically duplicated for another institution. The ASP and Pittsburgh's philosophy faculty responded that any publications in the collections had to be viewed as integral parts of them both intellectually and physically. They argued that fair-use provisions permitted duplicating such publications in order to preserve the integrity of the archival whole. Professor William Nasri, a noted expert on copyright in the university's School of Library and Information Science, agreed. His opinion, coupled with careful lobbying by local philosophers, eventually led the University Counsel's office to rethink its position.

Another obstacle stood in the way, though. In part because of its staterelated status, the University of Pittsburgh awarded contracts for expensive outside work on a competitive basis. Specifications for a costly project were submitted to open bidding, and the lowest qualified bidder received the contract. This procedure posed serious problems for microfilming the ASP's collections, which certainly would be an expensive undertaking. After careful investigation, it was clear that UMI was best suited to perform this work. Moreover, nationally recognized experts had warned the ASP's curator that some vendors claiming to perform preservation microfilming did not always adhere to established standards. Certain other vendors, they insisted, had a good reputation, but the overall quality of their output had slipped. Therefore, if Pittsburgh followed its normal procedures, it was quite possible that one of these problematic vendors would receive the contract to microfilm the ASP's collections. That outcome was unacceptable to everyone in Pittsburgh and Konstanz involved with the collaboration. Appeals were made to both the provost and the director of the university's purchasing department to grant an exception to the competitive bidding rule. It helped that the provost was already well informed about the ASP's collaboration with Konstanz and that he appreciated its scholarly significance. In the end, an exception was granted, and UMI's services were engaged, but only after the microfilming had been delayed considerably.

After the internal obstacles had been overcome, implementing the partnership was relatively straightforward. Its success was due to the inter-

10. 17 U.S.C. $\$ 108(b)$. For helpful discussion of this provision, see Gary M. Peterson and Trudy Huskamp Peterson, Archives \& Manuscripts: Law (Chicago: Society of American Archivists, 1985), 82-5. 
play of several important factors, some of which were institutional in nature. Philosophers at both Pittsburgh and Konstanz were solidly committed to the legacy of logical positivism. Members of the two philosophy departments knew each other well, were on cordial terms, and sometimes lectured or spent sabbaticals at the other university. Given such ties, it is not surprising that the idea of an archival partnership first arose in casual conversation between the two institutions' philosophers. The fact that each philosophy department was highly regarded internationally and was influential in its own institution was another important factor. The prominence of Konstanz's department certainly helped it secure the grant funding needed to train its curator and film Pittsburgh's collections. Moreover, with the help of the philosophy department concerned, local barriers to implementing the partnership were overcome more easily than they would have been otherwise. The important role that Pittsburgh's department played in surmounting opposition from the University Counsel's office, for example, is discussed above. It also was crucial that each philosophy department took an active interest in its archive. The curator of the ASP enjoyed a close working relationship with Pittsburgh's philosophy faculty, who promoted the collections at home and abroad, helped secure funding for new acquisitions, and offered much sound advice. The faculty members patiently learned about copyright issues, preservation standards, and other details of archival practice in order to become genuine partners in developing and supporting the ASP. A similar situation occurred in Konstanz. Just as important as the faculty's role, though, was the consistent support of Pittsburgh's library for the partnership. Members of the library administration and the Head of Special Collections, to whom the ASP's curator reported, regarded collaboration with Konstanz as a priority and became actively involved whenever their assistance was needed.Finally, Konstanz's commitment to follow American practices in everything from cataloging to access probably spared both curators a number of logistical difficulties in implementing the partnership.

Factors besides institutional ones were important for the partnership's success. The ASP curator's education and experience enabled him to train his counterpart in Konstanz and to support her from a distance. Thus, she could grow into her role with relative ease. This, in turn, resulted in a more professional and a more efficient level of interaction between them. The fact that Pittsburgh's curator spoke fluent German and used it in all communication with Konstanz also fostered efficiency and contributed to cordial working relationships there. His previous experience living and studying in Germany helped make his training visits go smoothly. In addi- 
tion, his graduate education in philosophy enabled him to talk the language, as it were, of philosophers at both institutions. This underlay much of the mutual respect that was essential for effective interaction with them. Although the knowledge, skills, and experience of the ASP's curator clearly facilitated collaboration, his counterpart at Konstanz also brought several essential qualities to the partnership. Her ingenuity, diligence, and flexibility enabled her to make substantial contributions after receiving only the limited training and professional support discussed. Moreover, her subject expertise has been indispensable in cataloging material, assisting researchers, and working with Konstanz's philosophy faculty. Communications technology also played a critical part in the partnership's success. Faxes, phone calls, and countless e-mails made possible the detailed planning and consultation needed at all stages of implementation. The same technology also enabled long-distance professional support of Konstanz's curator.

In sum, the success of the Pittsburgh-Konstanz archival partnership in its first years resulted from the interaction of institutional factors, curatorial expertise, and advances in communication. Although these same traits no doubt existed elsewhere, it is unusual that they occurred in combination with one another. Their coexistence most likely accounts for the unique quality of this particular collaboration. However, the experience gained in the Pittsburgh-Konstanz archival partnership and the its evident benefits recommend it as a model for developing other, similar partnerships across national and linguistic boundaries. ${ }^{11}$

11. The author served as curator of the Archives of Scientific Philosophy, University of Pittsburgh, from 1988 to 2001 . He thanks attendees of the 2004 RBMS Preconference, where he read a shorter version of this article, for their interest and helpful comments. Dr. Brigitte Parakenings, curator of the Philosophisches Archiv, University of Konstanz, also provided valuable suggestions for improving an earlier version. Last, but not least, thanks are due to the Special Collections Department, University of Pittsburgh Libraries, for supplying user statistics and other data.

\section{Jonathan Potter Limited-}

We Buy and Sell Maps, Plans, of most periods. advice, stock lists please also send us

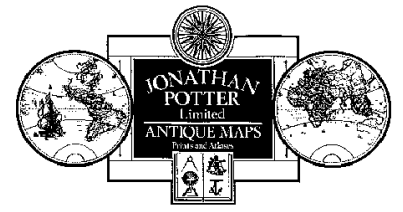

Interesting \& Rare Charts and Atlases

Contact us for and catalogues, your offers.

$125 \mathcal{N e w}$ Bond Street, London $W_{1} S$ 1DY, U.X. -

Tel: +44 (o) 2074913520 - Fax: +44 (o) 2074919754 -

E-mail:jpmaps@attglobal.net - Website: www.jpmaps.co.uk- 